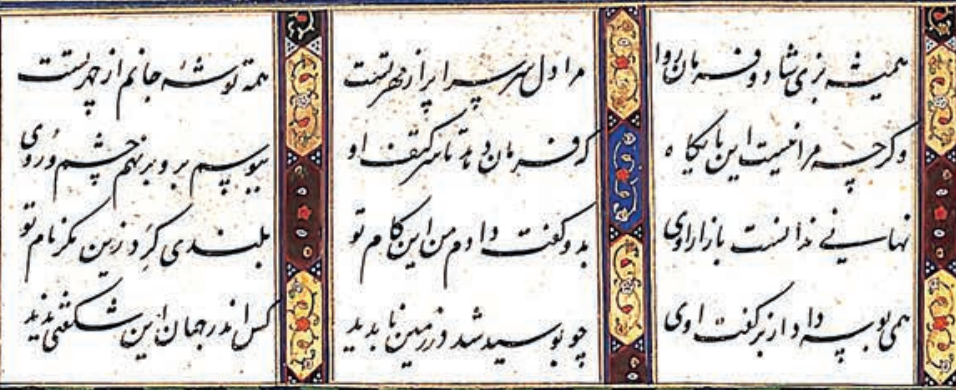

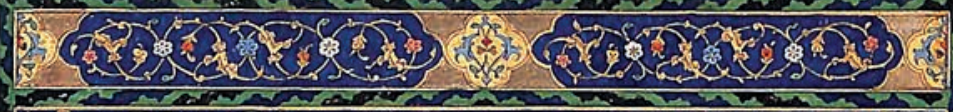

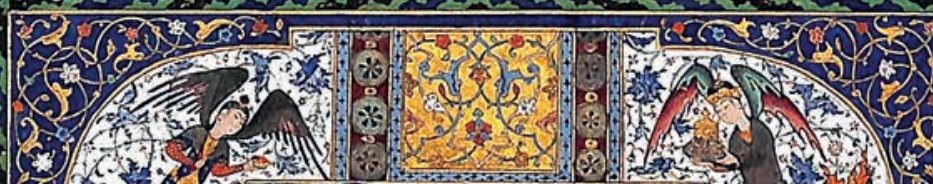

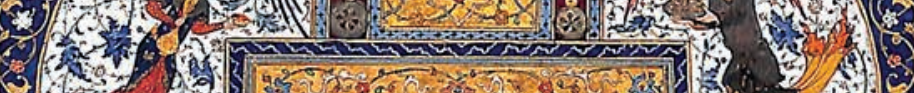

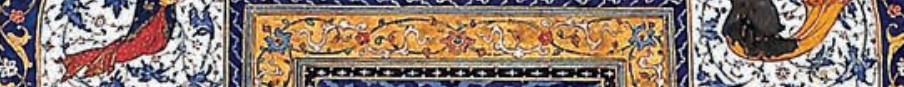

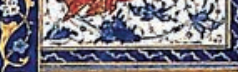

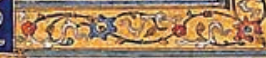
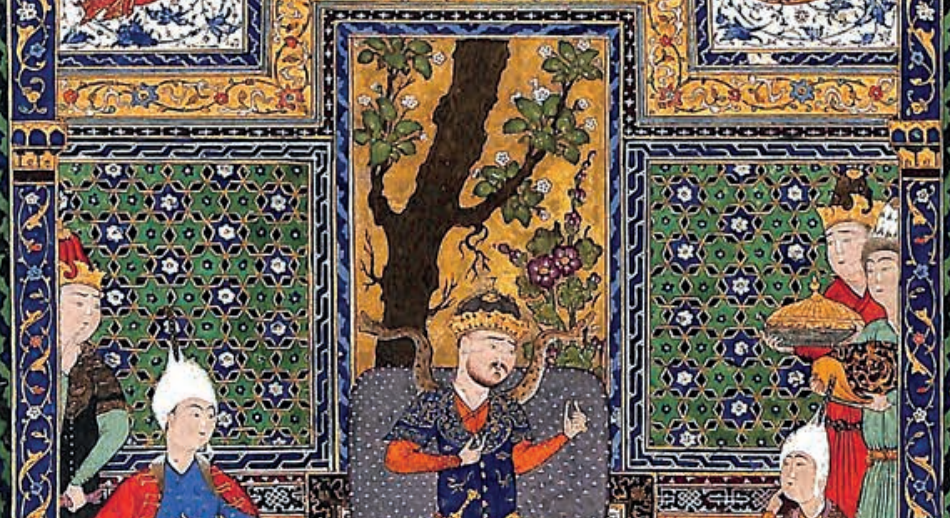

Lis.o.

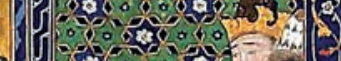
i is: ज, L

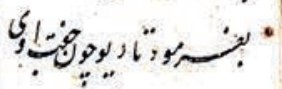
, :

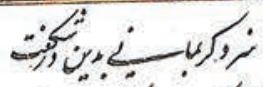
. 


\title{
Formar la lengua. Etimología, patria y lenguaje en El payador de Leopoldo Lugones
}

\author{
Forming Language. Etyimology, Homeland and Language \\ in Leopoldo Lugones' El payador
}

\author{
Diego Bentivegna \\ CONICET-Untref-UBA
}

\begin{abstract}
RESUMEN: El trabajo enfoca uno de los textos más importantes en la historia intelectual argentina - El payador, de Leopoldo Lugones, publicado en 1916, en ocasión del centenario de la independencia argentina- desde una perspectiva que privilegia lo glotopolítico y el análisis del discurso. Se detiene especialmente en el estudio de los planteamientos de Lugones en torno a la condición de la lengua castellana en América. Entiendo que esos planteamientos suponen posicionamientos críticos, explícitamente políticos, en el marco de la configuración de una hegemonía lingüística y literaria hispanista. En función de ello, se aborda también la postura de Lugones con respecto a la lengua en El payador en relación con la proyección de una filología desde la Argentina. Esa filología lugoniana debería asumir como objeto el castellano americano como entidad discursiva que, en diálogo con los grandes momentos de la disciplina en el ámbito de las diferentes lenguas romances y en un momento previo a la institucionalización de ese tipo de estudios en la Argentina, permite justificar las continuidades entre la tradición clásica y la cultura argentina a partir de la mediación de otros objetos como la poesía provenzal y la poesía gauchesca.
\end{abstract}

ABSTRACT: The paper focuses on one of the most important texts in Argentine intellectual history -El payador, by Leopoldo Lugones, published in 1916 on the occasion of the centenary of Argentine independence - from a perspective that favors glotopolytic and discourse analysis. It stops especially in the study of the proposals of Lugones on the condition of the Castilian language in America. I understand that these proposals represent critical, explicitly political positions within the framework of the configuration of a linguistic and literary hegemony in Spain. Accordingly, the position of Lugones with respect to language in El payador is also approached in relation to the projection of a philology from Argentina. This Lugonian philology should take as its object the American Castilian as a discursive entity that, in dialogue with the great moments of the discipline in the field of the different Romance languages and at a moment prior to the institutionalization of this type of studies in Argentina, allows to justify the continuities between the classic tradition and the Argentinean culture from the mediation of other objects like Provencal poetry and gauchesque poetry.

Palabras Clave: filología, castellano de América, literatura argentina.

KEYWORDS: philology, castilian in America, literature of Argentina.

RECIBIDO: 4 de marzo de 2017 • ACEPTADO: 11 de mayo de 2017 



\section{Diego Bentivegna \\ CONICET, Untref, UBA}

\section{Formar la lengua. Etimología, patria y lenguaje en El payador de Leopoldo Lugones}

1 .

El 29 de junio de 1919, las Sociedades Israelitas de Buenos Aires realizaron un acto en el teatro Victoria de la capital argentina. La razón del encuentro era manifestarse públicamente por las persecuciones a las comunidades judías de Europa oriental, sobre todo en Polonia y en Rumania, desencadenadas luego de la derrota de los imperios centrales y del conflictivo surgimiento de los nuevos estados nacionales. Uno de los oradores principales invitados al acto era Leopoldo Lugones, ya por entonces uno de los miembros centrales del campo literario argentino. Vida nuestra, entre los medios más importantes de la comunidad judía en la Argentina de la época, da cuenta de las palabras del escritor.

El discurso de Lugones, improvisado con extraordinaria elocuencia y con incomparable belleza de imágenes, motiva a cada instante frenéticas aclamaciones de la multitud. Evocó un pasaje magnífico de campo argentino, al encontrarse una tarde plácida en las cercanías de una colonia judía, con un israelita ruso, que reflejaba en su aspecto y en su humildad los viejos dolores de la raza. Aquel judío - dijo - que llevaba en su hombro al nietecillo de ojos profundos y cuya rubia cabellera anticipaba la primavera de los trigales, le contó la historia de las matanzas, de las cuales el triste emigrante sólo había salvado su gabán color café y su viejo paraguas. El orador había dicho, dirigiéndose al muchacho: "Este ya hablará el idisch". El judío 
había contestado: "No, porque ya no lo necesita". No lo necesita, añadió el orador, porque se halla en la tierra de la libertad, y en vez del idioma universal de la persecución, tan mezclado y tan pintoresco como la valija del buhonero, hablaba el castellano claro y hermoso, el idioma argentino, que es el idioma de la patria donde se fraterniza con el dolor y donde el oprimido es ante todo un hermano (Lugones 1919: 20).

El relato incluido en el resumen de la conferencia de Lugones en la publicación israelita condensa las tensiones que atraviesan el campo de las lenguas en la Argentina en los primeros años del siglo xx o, para decirlo con Maingueneau (2009: 182), su interlengua, las relaciones en una coyuntura dada las variedades de una misma lengua, así como la relación de una lengua con otras. En el caso del fragmento, la tensión se da entre las hablas de la dispersión - las hablas inmigratorias, vistas tanto unas como otras como extrañas con respecto a la comunidad imaginada nacional - , y el castellano, con su doble condición de lengua nacional y de lengua compartida con el resto de los estados nacionales surgidos del proceso de independencia de las antiguas colonias de la Corona española. El fragmento muestra otra de las tensiones que atraviesan las posiciones que asume Lugones en torno a la lengua: la tensión enunciativa entre los tiempos del relato desembragado (Maingueneau 2009: 250; Courtés 1997: 368), tiempos articulados alrededor del pretérito perfecto simple que dan cuenta de un pasado extranjero, doloroso y heteroglósico, asociado con el anciano que todavía viste al modo tradicional de los judíos orientales y, el presente, el tiempo del discurso, que corresponde al enunciado embragado y que remite al momento feliz de la integración patriótica de la niñez de origen inmigratorio en un universo monoglósico.

2.

La lengua castellana en su inflexión argentina es, para Lugones, el espacio simbólico donde se juega algo del orden de la nacionalidad. En la serie isotópica en la que se integra, el lexema "idish" se asocia, en la alocución pública de Lugones tal como es extractado por la publicación comunitaria, con una lengua que no puede adscribirse a orden estatal 
alguno, o demasiado anclada en un imaginario regional acotado o demasiado cosmopolita (es, en el sistema de equivalencias y de especificaciones que propone el texto, un "idioma universal", "de la persecución", "mezclado" y "pintoresco"). El habla de los judíos askenazis representa el peligro de devenir en una jerga que amenaza a la lengua y que se contrapone a otro espacio lingüístico, el del "castellano claro y hermoso". Desde su primer poema, Los mundos, publicado en una edición muy pequeña en Córdoba en 1893, el problema de la mundialización es una de las grandes obsesiones de Lugones, obsesión que se plasma en la división del planeta en bloques lingüísticos en expansión. Este espacio mundial es ocupado en parte por la lengua castellana, con la que se designa la variedad de una comunidad imaginada transnacional, que se pone en equivalencia con la expresión "idioma argentino". Designa en este caso el espacio de un "idioma nacional", una zona que Lugones había explorado en sus dimensiones históricas y políticas tres años antes en las conferencias que confluyen en el volumen El payador, en una vistosa intervención pública destinada a dejar una huella duradera en la cultura argentina. Ese idioma equivale, en el relato puntual del encuentro con el judío y en la construcción mítica que propone $E l$ payador, al "idioma de la patria".

La aparición del volumen en 1916, según las palabras del hijo de Lugones en la introducción a la edición de 1961, se "hizo coincidir con el centenario de nuestra independencia" (Lugones h. 1961: 5). En el desmesurado proyecto lugoniano, El payador forma parte de los textos patrióticos conmemorativos, que incluyen los textos apologéticos sobre Domingo Faustino Sarmiento, Florentino Ameghino y Julio Argentino Roca, y entra en serie con las intervenciones de manera explícita con los volúmenes que Lugones publica en 1910, como homenaje al centenario de la Revolución de Mayo: el Prometeo, la Didáctica, las Piedras liminares y las Odas seculares, que contiene la famosa "Oda a los ganados y los mieses", de uno de cuyos fragmentos ("Pasa por el camino el ruso Elías/Con su gabán eslavo y con sus botas [...]"; Lugones 1948: 439) el relato extractado en Vida nuestra es, evidentemente, una reescritura.

El payador ha sido leído, tal vez de manera demasiado mecánica, en función de los compromisos políticos autoritarios que el autor asumirá en los años veinte. El momento de inflexión de estas posiciones se 
plasma en el discurso de Ayacucho, que pronuncia Lugones, a cien años de la batalla en la que las últimas fuerzas realistas fueron derrotadas en Perú, como parte de sus alocuciones celebratorias, que lo llevarán, como se sabe, a apoyar de manera activa el golpe de Estado de 1930 contra Hipólito Yrigoyen. Se trata de un reposicionamiento, de un poeta relacionado con el aparato mismo del Estado y con la elite política, en la que la abjuración del arte por el arte del periodo modernista "clásico" y del anarquismo y el socialismo juveniles, materializado de manera extrema en La montaña (que dirige con José Ingenieros), se articula con la legitimación de un orden político conservador, heredado del roquismo. A un poeta que exaltaba y a la vez increpaba a las masas desde las cimas (Viñas 1982: 157), el mismo año de La montaña, 1897, desde otras cúspides, las de Las montañas del oro, el libro que aunaba prosa y poesía, con el que Lugones irrumpe como uno de los grandes componentes de la troika modernista de Buenos Aires (Carrilla 1967), junto con Rubén Darío y Ricardo Jaimes Freyre, corresponde, entre los centenarios de Mayo y de la Independencia, el poeta que opera como "agente de una íntima comunicación nacional entre las poesía del pueblo y la mente culta de la clase superior; que así es como se forma el espíritu de la patria" (Lugones 1961: 361), desde un escenario legitimado como espacio público: el Teatro Odeón de Buenos Aires, donde Lugones pronunció en 1913 las conferencias que darían base al libro de 1916, desde donde habían hablado intelectuales europeos de visita a la Argentina, como Anatole France y Georges Clemenceau.

Me propongo rastrear en El payador las tensiones que se plantean en lo que postula como una dimensión constitutiva de varias en el discurso de los intelectuales argentinos en los años del centenario de la independencia: las concepciones sobre las lenguas, que se articulan en un proceso de hegemonía lingüística (Gramsci 2013), marcado por el predominio cada vez más notorio de lo monoglósico. Las tensiones discursivas que relevamos operan en un plano que podemos pensar como glotopolítico (Arnoux 2000; Del Valle 2015). Ello implica, a su vez, instalarse en el marco del discurso social y asumir una perspectiva que se propone dar cuenta de sus objetos en términos de totalidad discursiva y "percibir los discursos en su omnipresencia y en su omnipotencia, difractados por todas partes, regulados por una hegemonía discursiva que 
tiene, sin embargo, por aquí y por allá, disfuncionamientos, desequilibrios, brechas, que las fuerzas homeostáticas perpetuamente tratan de subsanar" (Angenot 2010: 21). Supone, además, pensar las intervenciones en el espacio público y no como un discurso que adquiere su coherencia ideológica y su sentido último mediante la apelación a las posiciones personales y políticas de Lugones de manera directa, sino como una posición discursiva mediada por instancias ideológicas no subjetivas. Es importante notar, en este punto, no sólo las continuidades entre el Lugones de El payador y el Lugones de la hora del espada, continuidades que se manifiestan en la descripción de una guerra que es a la vez conflicto internacional y guerra civil permanente, sino notar también las huellas de un discurso emancipatorio y democratizador anclado en la noción de pueblo que desestabiliza la hegemonía discursiva conservadora, un discurso alternativo, nunca depurado, por cierto, de su contraparte elitista y aristocratizante. Es un discurso que se exhibe en parte de los escritos juveniles del poeta cordobés y que, de alguna manera, continúa operando en sus alocuciones de 1913, en una escenografía discursiva (Maingueneau 2009: 252) que evidencia la condición soberana del enunciador, ante la presencia intermitente del propio presidente de la república, Roque Sáenz Peña y de su ministro Indalecio Gómez, "autor de la ley electoral famosa, que conocemos con el nombre de aquel primer magistrado" (Lugones h. 1961: 5) y que abrirá la etapa de los gobiernos populares radicales de los años siguientes.

3.

En principio, en El payador, continúa operando la memoria discursiva de las discusiones que se plasman con fuerza en la Argentina a principios del siglo xx (Dobry 2010: 26), en torno a la publicación del volumen El idioma nacional de los argentinos, de Luciano Abeille (Oviedo 2005), por un lado, y a la disputa respecto a la fragmentación del castellano entre Rufino José Cuervo y Juan Valera, por otro (Del Valle y Gabriel-Stheeman 2004; Ennis y Pfänder 2013). Es una batalla por el idioma, para usar la expresión de Del Valle y Gabriel-Stheeman, que cruza el mundo hispánico y que será fundamental en las discusiones en torno a la legitimidad de la variedad argentina a partir de la fundación 
del Instituto de Filología de la Universidad de Buenos Aires y de la acción de sus directores más conspicuos: los españoles Américo Castro y Amado Alonso. Si en 1937, Borges — muchas de cuyas posiciones con respecto a la lengua y la cultura argentina retoman, la mayor parte de las veces sin explicitarla, la herencia lugoniana (Rodríguez 2006; López 2009) - reconoce que toda la poesía argentina del siglo xx surge del Lunario sentimental de 1909 (Borges 1955: 78), otro tanto podría decirse en lo que se refiere a las posiciones sobre el lenguaje que el poeta cordobés asume en El payador y sus huellas en las discusiones sobre la lengua argentina y las tensiones con las Academias de la Lengua y con las instituciones filológicas. Las conferencias de Lugones y su insistencia en una reflexión sobre la lengua argentina permiten ligar, en este sentido, las reacciones de la ciudad letrada argentina hacia Abeille y las polémicas con la autoridad académica y con los detentores de las herramientas filológicas legitimadas. En efecto, la opción de Lugones no será pensar esa lengua americana en su autonomía en relación con la española (la argentina no es, en este sentido, "otra lengua"), sino, y allí radica, entiendo, la potencia política de la postura lugoniana que, más allá de sus derivas evidentemente autoritarias, explica su valoración relativa por intelectuales cercanos al peronismo que vuelven a replantear el problema del idioma nacional, como Arturo Cambours Ocampo, o aquellos inscritos en el ámbito del pensamiento crítico latinoamericano de raigambre marxista, como José Carlos Mariátegui y Manuel Ugarte y, más tarde, Juan José Hernández Arregui y Jorge Abelardo Ramos, en su minoridad.

4.

Ya en el prólogo del volumen, del que suele destacarse la famosa referencia a la "plebe ultramarina, que a semejanza de los mendigos ingratos, nos armaba escándalo en el zaguán” (Lugones 1961: 17), Lugones reivindica, en la senda del romanticismo de lengua alemana y de Ernest Renan en su Origen del lenguaje, el lugar de los poetas que surgen del pueblo mismo en la configuración de otro idioma, "tal como este idioma resultó al principio otro latín y ello por agencia, también, de los poetas populares" (Lugones 1961: 18). Si, como sostiene Dominique 
Maingueneau, "a literatura desempenha um papel capital nesse processo de delimitaçao das línguas" en la medida en que "para surgir uma língua como totalidade, para que se tracem as fronteiras de um espaço estabilizado, vinculado com uma comunidade, é necessaia a referência a um corpus, um ambiente de uso restrito e prestigioso, particularmente uma literatura"2 (Maingueneau 2009: 197), la legitimación por parte de Lugones del Martín Fierro, aunque no de la gauchesca en general (Dobry 2010: 26), asume un rol central en un proceso que intenta articular, desde su lugar de "literato pedagogo" (Bombini 2004; Dalmaroni 2006), pueblo e idioma, en una confluencia lingüístico-política postulada por una concepción que se remonta al romanticismo de Herder y que "trataba de aclarar algo oscuro (el concepto de pueblo) con algo todavía más oscuro (el concepto de lengua)" (Agamben 2001: 50). Lo hace no sólo por los posicionamientos explícitos que El payador plantea en relación con el problema de la lengua, sino también por la confirmación de un determinado sector de la producción literaria como un cuerpo textual específicamente nacional, que permite demarcar una literatura propia, del mismo modo en que, en otro plano lo puede hacer un territorio, una dimensión glotopolítica explícita. Esa construcción no pone el acento en la "invención" de voces peculiares, en la línea de los americanismos léxicos tolerados en el marco de los instrumentos lingüísticos - diccionarios y gramáticas - hispánicos que Lugones se encargará de desfiliar en relación a las lenguas americanas (Dobry 2010), sino más bien en una dilucidación del trabajo interno sobre la lengua, que implica el "hallazgo de nuevos medios de expresión" (Lugones 1961: 15).

Al mismo tiempo, en la crónica que publica La Nación una vez terminado el ciclo de conferencias, se destaca un párrafo finalmente no incluido en la edición de El payador, en el que se refiere específicamente el problema de la lengua. En este sentido, Lugones, según la crónica del diario de los Mitre, sostiene de manera explícita la necesidad de poner en marcha la maquinaria filológica en relación con la edición de un texto,

\footnotetext{
1 "la literatura desempeña un rol capital en ese proceso de delimitación de las lenguas $[\ldots]$ ".

2 "para surgir una lengua como totalidad, para que se tracen las fronteras de un espacio estabilizado, vinculado con una comunidad, es necesario la referencia a un corpus, un ambiente de uso restringido y prestigioso, en especial una literatura".
} 
como el del Martín Fierro, que considera como fundamento de la cultura argentina. Así, a la tarea crítica exaltatoria desplegada por el propio Lugones durante sus conferencias y a su ethos de poeta-hermeneuta (Terán 2009), en condiciones de deslindar el núcleo significativo ("el secreto de su destino") de la cultura nacional sobre la base del gaucho y de su lucha histórica con el indio, tendría que continuar una actividad más reposada y menos vistosa, que el propio poeta había proyectado en los dos volúmenes que debían seguir al de 1916: el volumen dedicado al "léxico razonado del lenguaje gaucho en que está el poema compuesto" y el previsto para "al poema mismo comentado con notas ilustrativas de su sentido cuando éste resulte dudoso" (Lugones 1961: 16).

\section{5 .}

Lugones dirime, de esta manera, rumbos futuros para una lexicografía y una filología argentinas, que serán asumidos por especialistas formados en los rigores del método histórico de la escuela hispánica de Ramón Menéndez Pidal (Del Valle 2004: 109), con quien se discute en las páginas de El payador dedicadas a la cuestión de la lengua: el de la confrontación de fuentes y la compulsa de manuscritos, para obtener una "expurgación prolija y una anotación apropiada", como pide perentoriamente Lugones, del poema hernandiano, arruinado, en gran parte, por un tipo de circulación y de apropiación popular criollista (Prieto 1988) que sin duda, para Lugones, es perjudicial. A la tarea fundacional del poeta continúan el trabajo opaco del filólogo y del gramático, que en las décadas siguientes llevarán adelante expertos como Eleuterio Tiscornia, con su Martín Fierro comentado y anotado, de 1925, y con su estudio sobre La lengua del Martín Fierro, de 1930, publicado en la colección de estudios dialectológicos impulsada por Amado Alonso desde el Instituto de Filología.

En este sentido, la orientación glotopolítica de Lugones choca con la que sostendrá más tarde la filología institucionalizada, de cuyos engranajes participan los estudios de Tiscornia. Lugones, en efecto, intenta dar en El payador, un paso que no remeda los pasos de la filología hispánica. El programa filológico americano esbozado en El payador debería asumir tareas que están en la contracara del trabajo efectivo que 
se realizaría con la instalación en 1923 del Instituto de Filología de la Universidad de Buenos Aires, impulsado por Ricardo Rojas (generador, junto Lugones, de la revalorización del Martín Fierro a partir de su pertenencia a la épica; Sarlo y Altamirano 1997: 162 y ss.). Así como el gaucho representa una figura racial de transición entre el europeo y el argentino actual, del que es al mismo tiempo el "prototipo" (Lugones 1961: 79), el poema de Hernández, por su parte,

[...] será la fuente del futuro idioma nacional. Esto, como todo cuanto se refiere a la docencia general, es un deber del gobierno. Merece, por lo menos, tanta atención como nuestros jardines públicos y nuestros bosques de yerba mate. Es necesario, al mismo tiempo, crear en nuestra facultad de letras dos o tres cátedras de lenguas indígenas, no sólo por la importancia que ellas han tenido y tienen en la formación de nuestro idioma, sino para contribuir con los elementos que poseemos al progreso de la filología comparada (Lugones 1961: 359).

En rigor, la "importancia" que las lenguas indígenas han tenido, que en el fragmento de Lugones aparece como un efecto de preconstruido discursivo (Pêcheux 1975), tratará de ser atenuada por Lugones a lo largo de El payador y de sus intervenciones posteriores. Su lugar es, más bien, el archivo filológico, lo que enfatiza su carácter documental para el desarrollo de la filología comparada.

Julio Ramos (1996) ha leído un cuento clave en la producción de Lugones, "Yzur" (incluido en Las fuerzas extrañas, de 1906), como una alegoría de las posibilidades de intervención pedagógica del sujeto letrado (el narrador, una suerte de lingüista y antropólogo autodidacta) sobre el cuerpo de la lengua de los sectores subalternos, lengua caracterizada por la heteroglosia asociada con la presencia de grandes contingentes de inmigrantes (italianos, eslavos, españoles no castellanos, etcétera). A las variedades asociadas con la inmigración transatlántica apuntada por Ramos que se intenta incorporar al "espacio racionalizado-administrado de la lengua nacional" (Ramos 1996: 9), hay que sumar en Lugones y en los letrados pedagogos contemporáneos la voluntad de intervenir y purificar la presencia de elementos heteroglósicos provenientes de las diferentes variedades americanas. No se trata, para Lugones ("defensor protofascista de la pureza de la lengua”, aclara Ramos 1996: 4), 
de retomar como lenguas de expresión "culta" a las lenguas indígenas, sometidas luego de la campaña militar de 1879 (de la que Lugones en El payador, muchos años antes de la escritura de la biografía del general Roca que dejará sin terminar, es uno de los más firmes apologetas: "la ocupación de la Patagonia, resultó, pues, una verdadera 'conquista del desierto" "; Lugones 1961: 57), a un implacable proceso de museificación (en el que participan fundamentales en la conformación de los estudios antropológicos en la Argentina, como Adán Quiroga, Samuel Lafone y Quevedo y Roberto Lehmann Nitsche), del que el modernismo es estrictamente contemporáneo. El gesto lugoniano consiste en demarcar el idioma patrio de las lenguas indígenas. El gaucho como sujeto histórico es, aunque producto evidente del mestizaje entre europeos e indígenas, preponderantemente español, algo que se manifestaría en sus nombres propios, que se ven no como el producto de la hegemonía lingüística de las elites criollas, sino como un proceso natural de nominación (Lugones 1961: 57).

Tampoco se trata de recaer en un gauchismo afectado, de escribir "sistemáticamente en gaucho", sino de ser consciente que la literatura implica, en algún punto, el diálogo con los muertos, compensar su trabajo (Lugones 1961: 352). El gaucho es, para Lugones, como el indio, una figura del pasado, cuya función histórica desaparece con la imposición del Estado a partir del roquismo. "Su desaparición - afirma - es un bien para el país, porque contenía un elemento inferior en su parte de sangre indígena; pero su definición como tipo nacional acentuó en forma irrevocable, que, es decir, étnica y socialmente, nuestra separación de España, constituyéndonos una personalidad propia" (Lugones 1961: 83). Y es que la reposición del gaucho es una opción melancólica, la opción de un criollismo "plebeyo" que, como hemos trabajado en otro lugar (Bentivegna 2017), impugna ya en sus escritos juveniles del periodo socialista. Se trata, por el contrario, de dar forma a un idioma, sobre la base de la ecuación lengua-pueblo-nación.

6.

La legitimación de una cultura nacional sustentada en el gaucho como sujeto colectivo y como plasmación histórica y racial de un pueblo, im- 
plica en cambio para Lugones la legitimación de una lengua nacional, que, más que con rasgos diferenciales en relación con la lengua española común, se piensa como una operación en relación con el castellano como lengua mayor. En este punto, la lectura que Lugones hijo plantea de la cuestión de la lengua en las conferencias, establece su relación con los escritos "en materia de semántica" en el Boletín de la Educación Común a partir de 1931, como forma de intervenir en el campo pedagógico a través de un órgano que llegaba a la red de escuelas primarias estatales de todo el país, reunidas luego en el póstumo Diccionario etimológico, publicado en 1944, en un tono de impugnación de los "barbarismos" y los "solecismos" y en el ideologema (Angenot 1982) de "barbarie idiomática", asociado típicamente con la variedad argentina - un rasgo que La peculiaridad lingüística rioplatense de Américo Castro llevará al paroxismo-, y, en lo puntual, con la variedad porteña (Lugones h. 1961: 9).

Sin embargo, la orientación argumentativa de las posturas sobre el lenguaje en El payador parece ir en otra dirección, menos correctiva. No se trata, en este punto, de argumentar la existencia de un idioma nuevo, sino de una legitimación del castellano americano que Lugones piensa en términos históricos y políticos.

El idioma, en efecto, en Lugones, no aparece desligado de lo histórico, así como tampoco de lo estilístico, es decir, de las operaciones poéticas sobre la lengua, que hacen del poeta la figura determinante en la articulación de lengua, pueblo y nación. Esta apertura hacia lo literario aflora ya en el primer capítulo de El payador, donde Lugones plantea una serie de nociones generales sobre el lenguaje. Sostiene allí el carácter del lenguaje como "valor humano por excelencia", que debe pensarse en función de la vitalidad de una raza y de una nación. De ahí que el Martín Fierro ocupe un rol central en el proyecto de la configuración de un entramado en el que raza, nación y lengua confluyen y se justifican mutuamente (Agamben 2001), deslindándose tanto de la matriz hispánica como de las lenguas indígenas, las lenguas de la barbarie y las lenguas de inmigración que de alguna manera pueden horadarlo.

Lugones debe sostener así el lugar determinante de la poesía en la configuración de lenguas y naciones, apropiándose para ello - como lo demuestra en 1910 en el Prometeo- de algunos aspectos de las 
elaboraciones de la filología comparatista del siglo XIX, en especial de las teorías de Ernest Renan y de Max Müller (Olender 2005). En El payador, Lugones recuerda que el latín "se transformó en los actuales romances que son nuestros idiomas latinos, por medio de la poesía. De empezar a cantarlo en coplas, con otros ritmos que los clásicos, es decir, adaptándolo a las tonadas regionales, provino la transformación. La rima, desconocida por el latín clásico, constituyó, precisamente, el otro elemento. Las primeras lenguas romanas, fueron habladas en verso" (Lugones 1961: 43). Por eso, la función del poeta no es tan sólo la del hermeneuta, habilitado a través de su contacto con una verdad primigenia (Terán 2009), sino también la de aquel que está en condiciones de legitimar el uso lingüístico a partir de su praxis concreta, de la acción de los hombres originarios, que la filología del siglo XIX veía como instauradores de las lenguas. ${ }^{3}$

El verso estuvo siempre a la cabeza del movimiento evolutivo, como lo demuestran La Canción de Rolando y el Romancero. Antes que en ningún otra parte, el francés y el castellano de hoy encontrábanse ya en aquellos poemas. Ellos popularizaron esos nuevos idiomas, autorizando con el cuño del arte, los elementos populares resultantes de la deformación del latín por los indoctos, y de su mestización con los dialectos regionales. Sin esa intervención del elemento superior y original, la barbarie habría permanecido inmóvil, como la tierra donde arraiga el árbol; pues éste es el elemento activo de transformación, al representar una vida superior respecto a la tierra. Por último, la Divina Comedia formó definitivamente el italiano, sólo con tomar como vehículo el dialecto de la Toscana. Así convertido en obra de arte, fue el organismo superior destinado al triunfo" (Lugones 1961: 43-44).

Poesía, acción del genio y configuración de una lengua nacional constituyen un bloque glotopolítico, en el que El payador se propone intervenir:

Así, por ejemplo, en Ernest Renan: "Cuanto más se penetre en el conocimiento de la remota antigüedad de los pueblos arios y semíticos, más se verán esbozadas en la aparente uniformidad del mundo primitivo las figuras de los sabios, de los iniciadores, de los profetas sin nombre, a los cuales las leyes, las costumbres, las instituciones de la vida civil y religiosa, las poesías sagradas se relacionan como inspiradores suyos" (Renan 1946: 18). 
Nuestro castellano, menos correcto que el de los españoles, aventájalo en eficacia como instrumento de expresión, al resultar más acorde con las exigencias de una vida más premiosa: que tal, y por la misma exigencia ineludible de progreso, fue, desde la conquista, la vida americana (Lugones 1961: 169).

En el razonamiento argumentativo que despliega El payador, la conquista española de América es leída más como una ruptura en relación con la España del Siglo de Oro y de la modernidad que como una continuidad. En este aspecto, el discurso sobre el lenguaje que Lugones despliega en El payador se articula con el discurso emancipatorio de las guerras de independencia (Arnoux 2008), lo reactiva, algo que hace explícito en otro texto que Lugones de 1916, leído también públicamente, en este caso en ocasión de la muerte de Rubén Darío (Dobry 2010; Bentivegna 2017).

En esa alocución, Lugones ubica a Darío en la serie de los libertadores de América. Opera, de esta manera, la memoria discursiva de la emancipación de las ex colonias españolas (Arnoux 2008), una memoria que en la década del 20 reactivarán tanto Lugones como Ingenieros, con sentidos opuestos. Lugones lo hará en función de un nacionalismo abierto a un panamericanismo que se adecua a los intereses estadounidenses; Ingenieros, junto con el mexicano José Vasconcelos, en aras de la construcción de una Unión Latinoamericana, que ve en el imperialismo norteamericano el peligro principal para los países del sur del continente. El discurso literario no funciona, en este sentido, como un espacio refractario a lo político, pero tampoco como su mero reflejo. Como en El payador, es la posición misma del sujeto que enuncia en el linde entre el campo literario y el político, en la posición del poeta-hermeneuta, lo que adquiere un carácter de intervención pública, y sus operaciones sobre el material con el que opera, sobre la lengua, lo que adquiere una dimensión política explícita. En El payador, a diferencia de las intervenciones de los años posteriores, ese componente asume como legado americano la herencia de la libertad y de la democracia (Rodríguez 2006: 51), opuesta de manera explícita al "castellano paralítico de la Academia", que "corresponde a la España fanática y absolutista, nuestra madrasta", como decía con tanta propiedad Sarmiento; 
y en eso, como en todo lo demás, sólo le debemos atraso y desolación" (Lugones 1961: 204).

7.

En la Didáctica de 1910 Lugones insistía en la crítica a la Academia, al mismo tiempo que postulaba la búsqueda de una variedad enseñable, una variedad nacional culta, que se distinguiera tanto de las hablas populares criollas como de la variedad hispánica (Lugones 1910: 246). La gramática en su versión académica, e incluso en la versión del "racionalismo superior" de Benot y Bello, fue incluida por Lugones en el campo de acción del "dogma de obediencia", y exhibe, de esta manera, una dimensión política evidente:

La gramática, como residuo del dogma claustral, es una tiranía. Basta ver la resistencia que los alumnos le oponen generalmente. Tienen razón. Compuesta por una serie de definiciones, su enseñanza no interesa. Es la eterna imposición de la obediencia, por medio de prescripciones inmóviles: el simulacro de raciocinio, que sólo significa una serie de posiciones ante fórmulas intangibles. Dios y el caso ablativo, existen. ¿Y si descubrimos como el otro, que Dios es una hipótesis inútil en matemáticas, o que el caso ablativo no existe sino en el texto gramatical? La misma Academia, en el suyo, no sabe bien para qué sirve [...] (Lugones 1910: 249).

Al mismo tiempo que una crítica a las posiciones dogmáticas de la Academia, Lugones plantea un rechazo a las variedades orales, tanto urbanas como rurales efectivamente existentes, a diferencia de la lengua imaginada del gaucho, anterior a la configuración del Estado argentino. De este modo, aunque impugna la autoridad de la Academia, prescribe el uso de su diccionario como instrumento para corregir errores de dicción habituales en la Argentina, como el uso de "endija" por "rendija" o de "erro" por "yerro", así como de léxico regional, como "laucha" por "ratón".

Lugones no especifica, sin embargo, un modelo de lengua culta enseñable en el sistema escolar argentino. En El payador, por el contrario, se detiene en el carácter didáctico de la poesía "gaucha" como agente de civilización que opera más allá de la institución escolar y 
que relaciona, en una posición cercana a la concepción romántica, más con la educación musical que con la enseñanza letrada de una variedad lingüística culta: "Representa para el campesino las letras antes de la lectura, la estética como elemento primordial de la enseñanza" (Lugones 1961: 139).

8.

En El payador, la lengua de la patria se imagina, en cambio, como un objeto histórico en relación con la lengua del Martín Fierro que posibilita imaginar una "civilización previa"; una comunidad "perdida", que dibuja una línea con la literatura caballaresca, con la poesía provenzal y, más atrás, como ya lo había desarrollado en detalle el propio Lugones en su Prometeo (un hijo del sol), publicado - recordemos - en ocasión de los festejos del Centenario de la Independencia argentina en 1910, con la antigua Grecia. Se deslegitima, desde una perspectiva para la que los fenómenos relacionados con el lenguaje adquieren una dimensión inmediatamente política, la idea de una suerte de "regreso" a la madre patria española, asociada con la ruta hispanista, que el 98 había vuelto a plantear como opción cultural y política concreta. "En pleno siglo XVII, considerábamos y éramos distintos" (Lugones 1961: 205).

En rigor, para Lugones, la emancipación es parte de un proceso de separación entre la América democrática y libre y la España, sometida históricamente al "dogma de obediencia", que relaciona con el énfasis de la "raza gótica" por la verdad y con el cruce de ésta con el pensamiento cristiano, opuesto para Lugones al helenismo, en el que inscribe al Martín Fierro y a la cultura nacional legítima, centrado en los valores de belleza y libertad.

Lo que nosotros restauramos y seguimos restaurando, es la civilización por ella [España] perdida; de manera que todo esfuerzo por vincularnos a su decadencia, nos perjudicaría como una negación de aquel fenómeno. Es ella quien tiene que venir a nosotros, la raza nueva, "la hija más hermosa de una hermosa madre"; pero sin ningún propósito de influir sobre nuestro espíritu, más fuerte y más libre que el suyo. América no será jamás una nueva España. Podría derramarse en ella toda la población de la Península, sin que por esto se modificara su entidad (Lugones 1961: 204). 
Las digresiones sobre el lenguaje del Martín Fierro permiten a Lugones pensar al mismo tiempo continuidades y rupturas, que se manifiestan discursivamente en modalizaciones del enunciado ${ }^{4}$ (Maingueneau 1980: 125 y ss.) y series de negaciones polifónicas. ${ }^{5}$ Por un lado, los posicionamientos en torno a la lengua permiten dar cuenta de la ruptura en relación con el bloque idiomático, tal como se ha ido configurando históricamente en España, como producto de acciones públicas, de políticas del lenguaje, que tienden a fijarla de acuerdo con patrones académicos. Al mismo tiempo, en su vacilación entre la asignación de esa lengua a un espacio argentino o a un espacio más amplio (el americano, en su dimensión continental), Lugones no resuelve la cuestión lingüística en una clausura estrictamente nacional; por el contrario, se ve obligado a introducir en la discusión el componente continental.

9.

Hay una serie de fenómenos con los que Lugones describe el español americano, en el que la pobreza de medios expresivos (entre los que enumera la movilidad, la tendencia a la concisión de las fórmulas fatalistas, el "crudo realismo", "pintoresco desarrollo en el seno de la naturaleza") se potencian como rasgos concretos de un habla diferencial y de una literatura propia. Así, en la visión de Lugones, las metáforas adquieren un carácter "docente [...] al formular los resultados de la experiencia", en relación con una práctica, con las "cosas nuevas" que rodean al nombre americano que, más que a la mudez, como al Lord de Chandos de Hofmmansthal, con el que, según algunas lecturas críticas, se inicia la tensión entre silencio y palabra que va a atravesar todo el siglo xx (Rella 1981), produce más bien un conjunto de mecanismos de minorización de la lengua, tales como los puntualizados por Deleuze y Guattari (1978) en el alemán de Kafka:

Los elementos expletivos del idioma cayeron, pues, en desuso; las frases usuales simplificáronse como bajo una recia mondadura, en elipsis características; el verbo amplificó su acción vivificadora, abarcando en extensas

"Lo que nosotros restauramos [...]"; "Es ella [España] la que debe venir a nosotros".

"América no será jamás una nueva España". 
conjugaciones todos los substantivos; la ley del menor esfuerzo imperó absolutamente, al faltar, con la literatura, toda autoridad preceptiva, y aquella síntesis espontánea deshizo, sin saberlo, la artificiosa superestructura humanista que latinizó el idioma y cegó sus fuentes vivas bajo los adornos retóricos (Lugones 1961: 197-198).

La vitalidad de la lengua americana se contrapone en Lugones a la subordinación de la variedad culta peninsular, a la "tiranía de la academia" y a la "estética del canon", que conduce al "desmedro" de su libertad.

Por otro lado, la lengua americana que Lugones recorre a partir del cuerpo textual de la gauchesca, le permite pensar también en términos de contigüidad, pero no exactamente en relación con el castellano como lengua regional e, incluso, mundial, como en esos mismos años plantea Amado Nervo en los informes que envía desde Europa al Ministerio de Instrucción mexicano (Nervo 1946), sino como objeto histórico y románico. En efecto, la latinización culta, relacionada con el humanismo y más tarde con el culteranismo y con las posiciones académicas, enfatiza más las diferencias que las continuidades entre las distintas variedades romances surgidas de la fragmentación del latín. La lengua culta de los letrados castellanos, sobre cuya base se sostiene el discurso de la unidad de la lengua propugnado por el hispanismo que se plasma en la Academia, polémicamente funciona más bien, para Lugones, como una instancia de fragmentación de la unidad cultural latina.

Las palabras tomadas de él [el latín] por los letrados de los diversos países, no fueron las mismas: de donde provinieron dificultad y confusión. Así fueron mucho más parecidos que los actuales, el castellano, el francés, el portugués, el rumano, el italiano y el provenzal anteriores al siglo XVI (Lugones 1961: 201).

Lejos de ser concebida como una variedad degenerada o degradada del castellano, la lengua de los gauchos se mantenía en un lugar primigenio y, en consecuencia, más auténtico. Restauraba, "sin saberlo, la unidad natural del idioma" (Lugones 1961: 202). El corte histórico a la evolución natural de la lengua que supone la serie de intervenciones académicas, cuya matriz Lugones reconoce en el humanismo 
latinizante del Renacimiento y en el culteranismo, no afecta las hablas rurales del continente, alejadas de los grandes centros poblados y sus usos cortesanos. Si, por un lado, conservan varias formas del "castellano viejo", por el otro, mantienen los pilares políticos y culturales asociados con las lenguas latinas, que Lugones resume en tres puntos: el heroísmo caballeresco, el culto a la mujer y el honor. Frente a la acción de la Iglesia, con su separación de alma y cuerpo y su intento de anular al individuo; y de los germanos, aliados a la anterior desde la Edad Media y de parecida índole, la lengua del gaucho como núcleo de una lengua nacional implica la apertura hacia los diversos aportes de todas las lenguas romances, "refundidos de nuevo en un molde semejante al primitivismo" y, al mismo tiempo, es un producto de la acción libre y espontánea "de las tendencias étnicas", del mismo modo que la "democracia", que, como "fórmula política del mundo actual, fue constituyéndose también en América" (Lugones 1961: 204) y de la que en los años posteriores Lugones abjurará.

10.

En diálogo con el panteón autoral argentino, desde la generación del 37 hasta el modernismo e interpelando al mismo tiempo a los miembros más prominentes del espacio político de su época, El payador de Lugones - junto con otras intervenciones del momento, como Blasón de Plata de Ricardo Rojas o El hombre mediocre, de José Ingenierosasume de manera explícita la custodia del archeion de los argentinos. Como discurso constituyente (Maingueneau 2009: 61) en una zona liminar en la que se cruzan política, crítica literaria, pedagogía y discurso estético, el texto de Lugones se presenta a sí mismo a la vez como fuente y como monumento de poder, capaz de orientar acciones culturales y políticas futuras y de dar un sentido integral y coherente a la nación. En este trabajo de instauración discursiva de su propia autoridad, la máquina etimológica cumplirá un rol crucial en el esquema argumentativo desplegado por Lugones en El payador. La etimología es, en efecto, el argumento fundamental que permite a Lugones, como permitirá más tarde a Heidegger en relación con el pensamiento de la lengua alemana, fijar los orígenes griegos de la cultura argentina en una mitología del 
origen y un momento originario identificable, "a partir del cual la historia, o mejor, cierta historia ha comenzado y al cual puede regresar" (Esposito 2015: 35). Este es un mecanismo que Lugones exhibe ya en la advertencia preliminar del volumen, donde se reconstruye una etimología posible de los términos payador y payada desde la lengua provenzal, para realizar luego una red de términos presentes en las diferentes lenguas románicas: palhada en portugués, baia y baiata en italiano, bajócura en rumano, bailler en francés, el italianismo bagatela y baya en castellano. El límite de la derivación etimológica desplegada por Lugones está en el griego paizo, juego infantil, relacionada a su vez con pez, pedos, niño. "Payador quiere decir, pues, trovador en los mejores sentidos" (Lugones 1961: 14).

"Formar el idioma, es cultivar aquel robusto tronco de la selva, vale decir, para convertirlo en planta frutal; no divertirse en esculpir astillas" (Lugones 1961: 355). Hace cien años, en plena guerra mundial y en el linde del siglo abierto por ella, Lugones postula así la legitimidad de la moderna literatura latinoamericana como formación diferencial en relación con la española, al mismo tiempo que exhibe las raíces comunes de un árbol latino que es refractario a las variedades americanas prehispánicas y que se extiende, no sólo desde Tierra del Fuego hasta el Río Grande, sino que también se pliega en un origen: llega, en efecto, hasta las costas del mediterráneo y llega, sobre todo, hasta los griegos y los poetas provenzales. A su modo, Lugones proyecta una Nueva Provenza complementaria y alternativa a la que recorre una parte de la modernidad literaria del siglo xx, desde Pound a Pasolini. El payador, en los propios avatares etimológicos del sustantivo que adopta como título, materializa la historia de los desplazamientos y los desvíos del lenguaje que, a partir de una formación filológica fragmentaria, Lugones intenta con mayor o menor fortuna reponer, con una orientación política explícita, que no se cierra en un espacio imaginario nacional, sino que se ve obligada a plantearse en términos continentales, aun cuando no se explaye en ese aspecto. Se trata de un proceso inmerso en la configuración hegemónica de un entramado cultural a través de una operación filológica que evidencia sus alcances políticos. Esta operación, que usa de manera discrecional y polémica los instrumentos provistos por el saber lingüístico de matriz histórico y positivista del siglo XIX, lucha, en 
un frente doble, contra la apropiación hispanista de la lengua y contra aquellos que acentúan sus derivas indigenistas e inmigratorias. Inscrito en la memoria discursiva de la emancipación que atraviesa el siglo XIX en América y anticipando las disputas en torno a la lengua nacional de los años veinte, El payador afirma la posibilidad de concebir una posición válida, al mismo tiempo diferencial, "originaria" y "primigenia", de un idioma para la nación argentina.

\section{Bibliografía}

Agamben, Giorgio (2001). Medios sin fin. Valencia, Pre-Textos.

Angenot, Marc (1982). La parole pamphlétaire. París, Payot.

- (2010). El discurso social. Los límites históricos de lo pensable y decible. Buenos Aires, Siglo XXI.

Arnoux, Elvira (2000). "La Glotopolítica: transformaciones de un campo disciplinario", en AA. vv., Lenguajes, teorías y prácticas. Buenos Aires, Instituto Superior del Profesorado "Dr. Joaquín V. González": 95-109.

- (2008). Los discursos sobre la nación y el lenguaje en la formación del Estado (Chile, 1842-1962). Estudio glotopolítico. Buenos Aires, Santiago Arcos.

Bentivegna, Diego (2017). "Estilo, metáforas, indicios: Lugones y sus posiciones frente a la lengua entre los dos siglos", en Valentín Días (ed.), Episodios críticos de la modernidad latinoamericana. Caseros, Eduntref: 17-28.

BombinI, Gustavo (2004). Los arrabales de la literatura. La historia de la enseñanza literaria en la escuela secundaria argentina. Buenos Aires, Miño y Dávila.

Borges, Jorge Luis (1955). Leopoldo Lugones. Buenos Aires, Troquel.

Carrilla, Emilio (1967). Una etapa decisiva de Darío (Rubén Darío en la Argentina). Madrid, Gredos.

COURTÉs, Joseph (1997). Análisis semiótico del discurso. Del enunciado a la enunciación. Madrid, Gredos.

Dalmaroni, Miguel (2006). Una república de las letras. Lugones, Rojas, Payró. Escritores argentinos y Estado. Buenos Aires, Beatriz Viterbo.

DoBRy, Edgardo (2010). Una profecía del pasado. Lugones y la invención del "linaje de Hércules". Buenos Aires, Fondo de Cultura Económica.

EnNIS, Juan Antonio y Stefan PFändER (2013). Lo criollo en cuestión. Filología e historia. Buenos Aires, Katatay. 
Esposito, Roberto (2015). Pensamiento viviente. Origen y actualidad de la filosofía italiana. Buenos Aires, Amorrortu.

Gramsci, Antonio (2013). Escritos sobre el lenguaje. Diego Bentivegna (ed.). Caseros, Eduntref.

López, María Pía (2009). "Paradojas de la fundación”, en L. Lugones, El payador. Buenos Aires, Biblioteca Nacional: 27-34.

Lugones, Leopoldo (1910). Didáctica. Buenos Aires, Otero.

- (1919). "La protesta contra la matanza de judíos: discurso de Leopoldo Lugones", Vida Nuestra. Buenos Aires, 3 de julio: 18-21.

- (1948). Obras poéticas completas. Madrid, Aguilar.

- (1961). El payador, con prólogo de Leopoldo Lugones (h.). Buenos Aires, Centurión.

Maingueneau, Dominique (1980). Introducción a los métodos de análisis del discurso. Buenos Aires, Hachette.

- (2009). Discurso literário. Sao Paulo, Contexto.

Nervo, Amado (1946). La lengua y la literatura, vol. II. La Plata, Calomino.

Olender, Maurice (2005). Las lenguas del paraíso. Buenos Aires-México, Fondo de Cultura Económica.

Oviedo, Gerardo (2005). "Luciano Abeille y el idioma nacional de los argentinos", en L. Abeille, Idioma nacional de los argentinos. Buenos Aires, Biblioteca Nacional.

PÊCHeux, Michel (1975). "Mises ou point et perspectives à propos de l'analyse automatique du discours". Mots, 9: 7-17.

Prieto, Adolfo (1988). El discurso criollista en la formación de la Argentina moderna. Buenos Aires, Sudamericana.

Ramos, Julio (1996). Paradojas de la letra. Caracas, eXcultura/Universidad Simón Bolívar.

RodríGuez PÉrsico, Adriana (2006). "El lugar (del) secreto: Leopoldo Lugones y las figuras de escritor", Cuadernos LI. RI. CO. Revista de la red interuniversitaria de estudios sobre las literaturas rioplatenses contemporáneas en Francia, año I, n. 1: 39-58.

ReLla, Franco (1981). Il silenzio e le parole. Il pensiero nel tempo della crisi. Milán, Feltrinelli.

Renan, Ernesto (1946). El origen del lenguaje. Buenos Aires, Albatros.

Sarlo, Beatriz y Carlos Altamirano (1997). Ensayos argentinos. De Sarmiento a la vanguardia. Buenos Aires, Ariel.

TERÁn, Oscar (2009), “El payador de Lugones o 'la mente que mueve montañas", en L. Lugones, El payador. Buenos Aires, Biblioteca Nacional: 23-16. 
VALLE, José del (2004). "Menéndez Pidal, la regeneración nacional y la utopía lingüística”, en José Del Valle y Luis Gabriel-Stheeman (eds.), La batalla del idioma. La intelectualidad hispánica ante la lengua. Frankfurt-Madrid, Vervuert Iberoamericana: 109-135.

- (ed.) (2015). Historia política del español. La creación de una lengua. Madrid, Aluvión.

Valle, José del y Luis Gabriel-Stheeman (eds.) (2004), La batalla del idioma. La intelectualidad hispánica ante la lengua. Frankfurt-Madrid, Vervuert Iberoamericana.

ViÑAS, David (1982). Literatura argentina y realidad política. Buenos Aires, Centro Editor de América Latina. 